Case Reports

\title{
Web-Based Emergency Management Information System for Landslides Occurrences
}

\author{
Jordan H. Souza, Carlos A.P. Soares, Gislaine Santos and Wainer S. Silva \\ School of Civil Engineering, UFF Federal Fluminense University, Niterói (RJ), Brazil
}

Article history

Received: 6-11-2016

Revised: 04-01-2017

Accepted: 11-01-2017

Corresponding Author:

Jordan H. Souza

School of Civil Engineering,

UFF Federal Fluminense

University, Niterói (RJ), Brazil

Email: jordan.souza@ufjf.edu.br

\begin{abstract}
Landslides cause significant human and environmental damage, as well as unpredictable damage to structures and buildings. This paper presents the development and application of a web-based system for risk management in landslide-related emergency preparedness. This system allows for easy access to information, even in hard-to-reach regions, by integrating mobile internet devices, like cell phones and tablets, with GPS systems, without requiring cartography or geoprocessing for its operation. Furthermore, in cases of imminent risk, the system can help prioritize the emergency response, so that scarce response resources can be allocated to the most vulnerable areas. A case study is carried out, demonstrating the benefits and difficulties of implementing this system for emergency response decision-making in urban scenarios with geotechnical risks.
\end{abstract}

Keywords: Geotechnical Maps, Environmental Analysis, Landslides, Risk Areas, Information Systems

\section{Introduction}

Landslides are a worldwide phenomenon (Foster et al., 2012), as can be seen in Table 1. Disasters caused by landslides have increased in recent decades, despite significant efforts from the United Nations to reduce their consequences (Cascini et al., 2005). Such disasters have caused death and economic damage, as shown in Table 2, which is taken from global landslide data from the Emergency Event Database (EM-DAT). EM-DAT is a worldwide database of disasters maintained by the Centre for Research on the Epidemiology of Disasters (CRED) that contains essential core data on the occurrence and impact of disasters in the world from 1900 to the present. The data are compiled from various sources.

Table 1. Number of countries that reported landslides to the Centre for Research on the Epidemiology of Disasters from 1900 to 2015. Source: CRED (2015)

\begin{tabular}{ll}
\hline Continent & Number of countries \\
\hline Africa & 19 \\
Americas & 21 \\
Asia & 27 \\
Europe & 18 \\
Oceania & 5 \\
Total & 90 \\
\hline
\end{tabular}

Table 2. Anthropic and economic damage associated with landslides between 1900 and 2015. Source: CRED (2015)

\begin{tabular}{llllll}
\hline Continent & Occurrence & Total deaths & Affected & Total affected & Total damage (in thousands USD) \\
\hline Africa & 34 & 1228 & 29389 & 58124 & N/A \\
Americas & 169 & 19842 & 5276327 & 5522527 & 2886727 \\
Asia & 360 & 23569 & 4137913 & 8095051 & 2869916 \\
Europe & 72 & 16662 & 29407 & 38498 & 3108889 \\
Oceania & 18 & 546 & 2263 & 20315 & 2466 \\
Total & 653 & 61847 & 9475299 & 13734515 & 8867998 \\
\hline
\end{tabular}


The CRED's criterion for entering a disaster into EM-DAT requires that at least one of the following conditions be fulfilled: (a) Ten (10) or more people must be reported killed, (b) a hundred (100) or more people must be reported affected, (c) a state of emergency must be declared, or (d) calls for international assistance must be made (CRED, 2015). In general, the number of registered landslide events is higher than the number presented in EM-DAT, since small landslide events may not meet the criteria for inclusion.

Increased concern with landslide emergency preparedness in several countries in recent years has led to the use of more modern technologies. Some examples are Assilzadeh et al. (2010), in Canada and Alexander et al. (2009), in Italy.

From EM-DAT records, it is evident that problems resulting from landslides are clearly not limited to underdeveloped or developing countries. The Mineral Resources Research Company (CPRM, 2011), a stateowned Brazilian company, undertook a study in 2011 to identify and classify Brazilian municipalities susceptible to mass movement. According to this study, about $26 \%$ of Brazilian municipalities are vulnerable to landslides (Table 3 ).

The landslides that have occurred in recent years in several states in Brazil have caused significant loss of life, as well as economic and social losses, including massive destruction of structures and buildings. In Rio de Janeiro, the most devastating disasters were observed in the mountainous regions. According to the WB (2012) and Netto et al. (2013), the torrential rains that fell in seven municipalities in the mountainous region of the state of Rio de Janeiro on 11 and 12 January 2011 caused landslides and the deaths of over 900 people and roughly 3 billion USD in material damages.

The events in Rio de Janeiro have been described in detail (Avelar et al., 2013). These accidents have raised a variety of questions related to emergency readiness and the techniques used to assess risk and monitor potential landslide areas (Lima, 2013; Dourado et al., 2014). Such events demand risk management procedures. Based on the approach proposed by Carvalho (2010), risk management should begin with strategic planning. After mapping risk areas, public policies for the preparation and evaluation of risk area projects must be formulated and adopted. It is essential that, at this point, information technology and geotechnical mapping should be involved in the preventive diagnose of high-risk areas.

Many Brazilian municipalities lack an adequate geotechnical mapping of high-risk areas (Cruden and Fell, 1997), despite many researchers having reported GIS and remote sensing tools for analyzing landslides (Odajima et al., 1998; Carrara et al., 1999; Van Westen, 2000; Lan et al., 2004; Nichol and Wong, 2005).
Table 3. Classification of Brazilian municipalities in accordance with landslide susceptibility risk

\begin{tabular}{lll}
\hline Categories & Number of cities & $\%$ Cities \\
\hline Very high & 161 & $26 \%$ \\
High & 90 & \\
Average & 1192 & \\
Low & 4156 & $74 \%$ \\
\hline
\end{tabular}

Properly designed web-based mobile systems integrated with GPS tools can provide fast, accurate and useful information in regions that are difficult to reach. Thus, it might be possible to provide accurate, up-to-date information to front-line emergency management personnel, both for emergency response planning and for aiding emergency response teams in the affected area. With these tools, operational teams can have full knowledge of terrain features and their geotechnical weaknesses even before reaching the emergency location.

To guarantee communication and data interchange between the networked computers and the end users in an emergency response team, a proper network architecture must be conceived. In the system presented in this paper, this task is achieved through the use of remote access that can host and distribute network services. Accessibility is guaranteed using standard internet protocols, such as the HyperText Transfer Protocol (HTTP) and File Transfer Protocol (FTP), for the system administrator interface and for system update procedures.

\section{System Design and Development}

Many commercial applications, such as ERDAS ErMapper ${ }^{\circledR}$ and ESRI ArcGIS ${ }^{\circledR}$, generate web-accessible cartographic data. Web-integrated GIS systems using this commercial software have been described (e.g., Tsou, 2004). However, the licensing cost of some of this software is incompatible with many municipality budgets. The authors decided to develop this system using free software: PHP and the MySQL database. This solution allows for the possibility of bringing landslide event evaluation to risk areas through automatic georeferencing. The implementation of the devised routing algorithm allows for the optimization of emergency response logistics.

Thus, a web-based risk management system has been designed with the following specifications:

- Reliability: THE system must be reliable, since it will store risk information that includes social and demographic information. Furthermore, the system must be able to determine whether a given point belongs to a previously mapped risk area

- User-friendliness: The system must be easy-touse by members of multidisciplinary teams and require little to no previous knowledge of geoprocessing. Since most of the end users 
(emergency management agencies personnel) will not have extensive geoprocessing or information technology knowledge, the working environment must be user friendly

- Portability: The server architecture must use PHP scripts and MySQL databases in Windows or Linux operating systems to ensure that it will be compatible with a wide range of available hardware. Arbitrary web services are those conducted through a single access point; all web service operations are executed through this single end point (Rettig et al., 2015)

- Maintainability: Source code should be written based on each documented function

- Code and storage: The geographic information stored in the database must be written in an optimal way, since there will be thousands of records

The web-based risk management system was used for Juiz de Fora city from 11/21/2006 under SISDEC 3.0 letters (PJF, 2016).

\section{System Architecture}

One of the key points of the system presented in this work is the integration of databases from the various offices taking part in emergency management tasks. This includes, for instance, fire departments, emergency management agencies and the planning and building departments in a given municipality, as well as the community at large. Further, integration at different levels of government (municipal, state and federal) might also be required.

Integrating inter-departmental databases allows the creation of a new paradigm for avoiding decentralization and the failure to integrate key information. The current state of affairs makes data access increasingly difficult and prevents integration, coherent updating and consistency checking (Sorensen, 2000). An additional advantage is that database conception and modeling can be unified, making it much easier to update, maintain and use.

Most server-side functions are implemented with PHP, an open source language for server scripting. These functions support different tasks, such as database interaction and back-end computation (Delmelle et al., 2014).

Tests with the new system architecture have shown that a system using PHP-MySQL allows the interoperation of all information, aiding real-time decision making. Information may be ranked according to factors like the event, neighborhood, or triage area for an event location.

Access to the system is available for official organizations, but not for the community, as shown in Fig. 1.

\section{System Development}

\section{Main Routines}

The system is structured as a group of main routines with predefined objectives. These are:

- Handling access requests

- Evaluating the geographic coordinates of a given location

- Defining an event's geographic extent

- Reading geometries or feature classes (points, lines, polygons, as well as tabular information) in the database

- Verifying whether a point belongs to a risk area polygon

- Creating jpeg format images for graphic visualizations

- Creating related information tables

- Presenting information and images using HTML

\section{Entity-Relationship Diagram}

Figure 2 presents the relationships between the geometrical entities from data input through the final presentation of compiled cartographic data for the end user.

\section{External Interfaces}

External access mainly occurs through an HTTP port (usually port 80 ), while the update module is accessed through the standard MySQL access port (usually port 3306). When updating, it is also possible to use a phpmyadmin script, thus avoiding proprietary commercial software for connecting to the MySQL database. This makes the system robust and portable and keeps it within the budget of most Brazilian municipalities.

\section{Cartographic base Development Module}

This module includes information containing the street layer of the area, neighborhood boundaries and place names. This information is displayed depending on the zoom level of the screen.

\section{Database Conversion Module}

One of the most difficult aspects of developing the type of application described in this work is maintaining intercommunication and compatibility between various databases. To solve this problem, a module to convert and insert data in the selected databases was developed. This intermediate application was developed on a Microsoft Visual Basic platform. See Table 4 for input variables.

Each graphical entity is printed in a specific table in the database. 


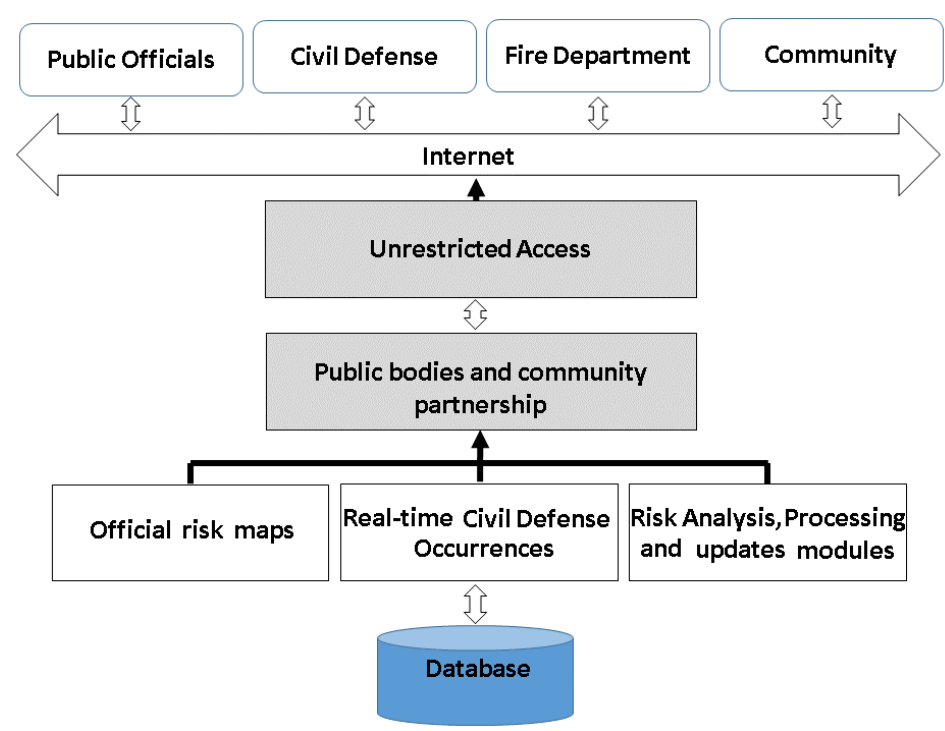

Fig. 1. Schematic of interactions between emergency management organizations and the community

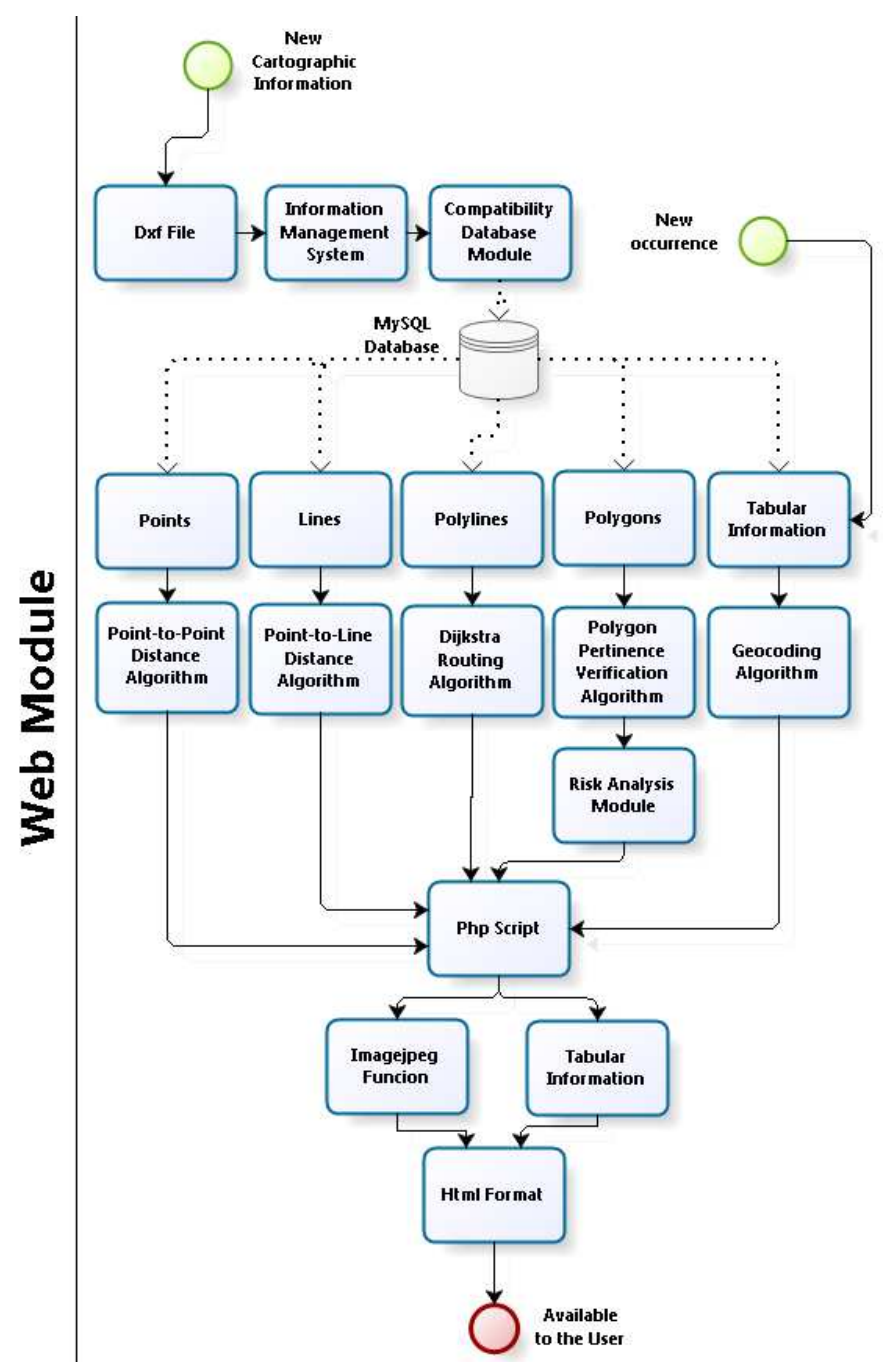

Fig. 2. Relationships between the various system processes 
Table 4. DXF Information used in intermediate application

Command
Arquivo DXF
Arquivo de Saída
Processar todos os arquivos DXF da pasta
Prefixo das Tabelas

\section{Geocoding Module}

Geocoding is the process of assigning a geographic code (e.g., coordinates) to a given place name by comparing its description to the descriptions of location-specific elements in a reference database (Karimi et al., 2004; Goldberg et al., 2007; Zandbergen, 2008). The process of geocoding uses different methods depending on the address and the availability of reference data.

This module provides geographic coordinates designed for text information that will be presented in the map. For buildings or land parcels that were not yet directly georeferenced, a linear interpolation between two adjacent city numbers was adopted, limited by a maximum distance between interpolation points. In this system, the authors use a cartographic map-based interpolation algorithm for the municipality georeference. Models of this type can be used to inform evacuation planning and emergency management at the local, provincial and federal levels of government (Tamima and Chouinard, 2012). Alternatives algorithms such as heuristic solutions (Kim et al., 2007; Yin, 2009) were not used in order to make the model more general.

\section{Risk Analysis Module}

In order to perform risk analysis, this module verifies the pertinence of the relation between the point being analyzed and risk area polygons, as well as historical risk indications of these areas.

From this point on, the system does not require any specialized intervention and is self-sustained by the continuous flux of emergency or evaluation reports.

Besides analyzing a point's pertinence to risk areas, this module also enables the localization of urban support installations, such as shelters and verifies the historical record of events at this point. The module checks for risks not only in the given area, but also in nearby regions.

During module design and testing, it was observed that risk analysis is a critical processing step, due to its high demand on processing capacity. In some cases, up to ten seconds of processing time was required to perform the complete geotechnical risk analysis. In this case, quad-core computers were required to make it possible to perform simultaneous analysis of other events. Storage use, on the other hand, is almost irrelevant, since vectorized data, for which little memory is required, is used for all analysis.
Description

DXF input file

Output file

Process all DXF files in a folder

Table prefix (optional)

\section{Interdependencies in the System}

\section{Interdependencies between Modules}

Figure 3 shows schematically the relationships between the various modules. It is assumed that, using the database developed for the system, the information management system is capable of migrating information from a vectorized format to the conventional database format. Since each vectorized element has its own handle, it is only possible to update items that have been edited, created or excluded in an update cycle.

\section{Data Interdependency}

There are relationships between the various data tables. It also presents the keys, indexes to tabular information, as well as geometrical entities from the DXF to MySQL database conversion.

\section{Case Study: Application of the System to the City of Juiz de Fora}

Juiz de Fora is the fourth largest municipality in the Brazilian state of Minas Gerais. According to 2009 data from the IBGE (Brazilian Institute for Geography and Statistics), it has an estimated population of 526,706 inhabitants and is the 36th largest city in Brazil. Juiz de Fora is highly urban, with about $99 \%$ of its population living in the urban area.

The municipality is located on the foothills of the Mantiqueira range. Its elevation varies from $467 \mathrm{~m}$ in the deepest valleys to $1,104 \mathrm{~m}$. The elevation of the city's downtown area is $678 \mathrm{~m}$. According to local emergency management services data, the yearly rainfall in the period between 2000 and 2007 ranged from 1500 to $2300 \mathrm{~mm}$. This indicates the variability of local rain incidence and the need to adopt risk management procedures. According to information from the municipal civil defense, the municipality has 76 areas of geotechnical risk for which rain is the trigger event.

The risk scenarios of the area are quite varied, depending on accumulated rainfall and the extent of the anthropic intervention in the area (Veyret, 2007).

\section{Development of the Cartographic Base}

Juiz de Fora's geographic space was characterized through the development of cartograms describing declivity, altimetry, risk susceptibility and an update to the mapping of areas of geotechnical risk. Until 2007, 
the official Datum for the municipality was the Córrego Alegre creek. Thus, all cartograms were developed using this Datum. The databases were developed in current geoprocessing applications, such as Spring, ArcGIS ${ }^{\circledR}$ and AutoCAD ${ }^{\circledR}$.

Using the database compatibility module, all databases were made compatible in such a way that at each geotechnical mapping update, the previous database could be replaced. During database conversion, an increase in data storage use was observed, due to the structured storage process, in which data repetition is relatively frequent. This contrasts with the previous storage structures, in which databases were structured to optimize data storage space.

\section{Geocoding Module}

Georeferences of 95,120 buildings in the studied area were created with a Location-Based Service (LBS) application, employing GPS equipment. Once this task was concluded, the table created was compared with the event record table and all related information and was coordinated by the comparison of addresses and street numbers and by the interpolation of these data.

\section{Risk Analysis Module}

From this stage, all reports filed with the emergency management authority were analyzed and subjected to the use of the LBS. Then, using new reports of field emergencies, the user was provided-before arriving at the emergency site-with a risk analysis map of the location (Fig. 4). All activities can be performed by users with no cartographic or geoprocessing training or knowledge.

The system presents the event report for emergency help after geocoding, presenting information related to existing risk areas, closer hydrants and additional information about local community shelters, if necessary.

Figure 4 shows the Grajaú, Vitorino Braga and Santa Cândida neighborhoods. The red target in the center of the figure indicates the building requiring help. The polygons in red, orange, yellow and green represent landslide risk classes to landslides: Very High, High, Medium and Low risk, respectively.

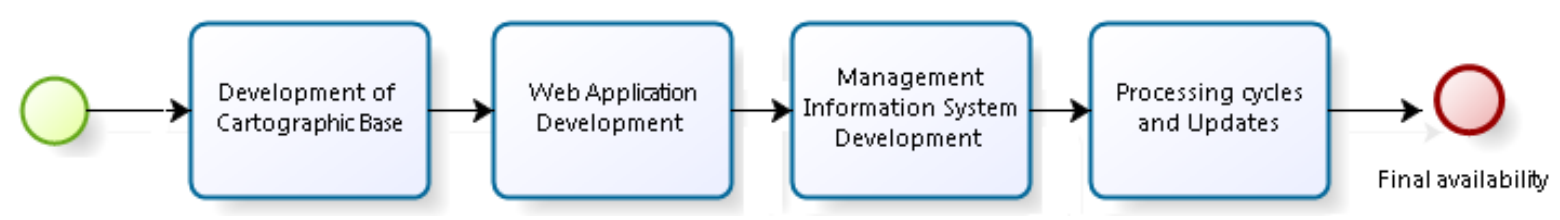

Fig. 3. Schematic presentation of the relationships between system modules

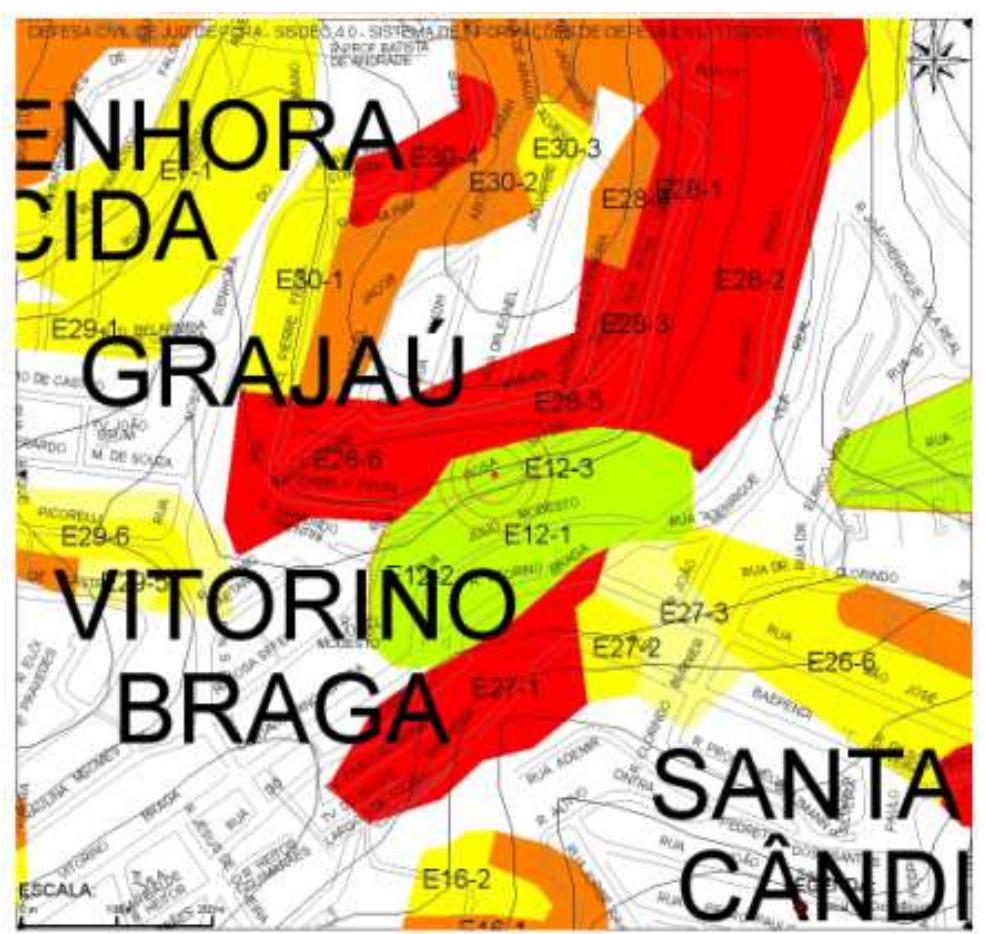

Fig. 4. Example of a scanned paper risk analysis map from the local emergency management authorities of Juiz de Fora 
Table 5. Response prioritization to occurrences from 2004 to 2015 and its impact on average response time

\begin{tabular}{|c|c|c|c|c|c|c|}
\hline $\begin{array}{l}\text { Semester/ } \\
\text { Year }\end{array}$ & $\begin{array}{l}\text { Number } \\
\text { of events }\end{array}$ & $\begin{array}{l}\text { Number of events } \\
\text { in risk areas }\end{array}$ & $\begin{array}{l}\text { Average response } \\
\text { time (in min.) }\end{array}$ & $\begin{array}{l}\text { Prioritizing based } \\
\text { on maps }\end{array}$ & $\begin{array}{l}\text { Prioritizing based } \\
\text { on response area }\end{array}$ & $\begin{array}{l}\text { Prioritizing based on } \\
\text { distribution by location }\end{array}$ \\
\hline $1 / 2004$ & 3065 & 2548 & 47,35 & & & \\
\hline $2 / 2004$ & 1205 & 969 & 44,27 & & & \\
\hline $1 / 2005$ & 1335 & 1046 & 48,99 & & & \\
\hline $2 / 2005$ & 1170 & 929 & 47,32 & & & \\
\hline $1 / 2006$ & 1161 & 897 & 42,35 & & & \\
\hline $2 / 2006$ & 1714 & 1343 & 49,5 & & & \\
\hline $1 / 2007$ & 3718 & 3100 & 35,97 & $\mathrm{x}$ & & \\
\hline $2 / 2007$ & 1999 & 1505 & 35,12 & $\mathrm{x}$ & & \\
\hline $1 / 2008$ & 2384 & 1735 & 34,89 & $\mathrm{x}$ & & \\
\hline $2 / 2008$ & 2148 & 1568 & 35,08 & $\mathrm{x}$ & & \\
\hline $1 / 2009$ & 1162 & 911 & 32,12 & $\mathrm{x}$ & $\mathrm{x}$ & \\
\hline $2 / 2009$ & 2084 & 1625 & 32,55 & $\mathrm{x}$ & $\mathrm{x}$ & \\
\hline $1 / 2010$ & 2099 & 1625 & 32,47 & $\mathrm{x}$ & $\mathrm{x}$ & \\
\hline $2 / 2010$ & 1470 & 1056 & 31,99 & $\mathrm{x}$ & $\mathrm{x}$ & \\
\hline $1 / 2011$ & 1936 & 1375 & 30,88 & $\mathrm{x}$ & $\mathrm{x}$ & $\mathrm{x}$ \\
\hline $2 / 2011$ & 1355 & 972 & 30,12 & $\mathrm{x}$ & $\mathrm{x}$ & $\mathrm{x}$ \\
\hline $1 / 2012$ & 1564 & 1143 & 30,29 & $\mathrm{x}$ & $\mathrm{x}$ & $\mathrm{x}$ \\
\hline $2 / 2012$ & 1521 & 1360 & 30,09 & $\mathrm{x}$ & $\mathrm{x}$ & $\mathrm{x}$ \\
\hline $1 / 2013$ & 1402 & 1125 & 30,07 & $\mathrm{x}$ & $\mathrm{x}$ & $\mathrm{x}$ \\
\hline $2 / 2013$ & 1139 & 1078 & 30,19 & $\mathrm{x}$ & $\mathrm{x}$ & $\mathrm{x}$ \\
\hline $1 / 2014$ & 1097 & 1176 & 31,12 & $\mathrm{x}$ & $\mathrm{x}$ & $\mathrm{x}$ \\
\hline $2 / 2014$ & 1088 & 1001 & 31,55 & $\mathrm{x}$ & $\mathrm{x}$ & $\mathrm{x}$ \\
\hline $1 / 2015$ & 1203 & 1049 & 29,36 & $\mathrm{x}$ & $\mathrm{x}$ & $\mathrm{x}$ \\
\hline
\end{tabular}

\section{System Performance Indicator}

To evaluate the efficiency of the system's performance, average response time was selected as indicator. This time is counted from the dispatch of the survey engineer from the emergency response installation to the conclusion of the local survey. In the case of a continued response, the time from the end of a survey to the conclusion of the subsequent survey is counted. These results are presented in Table 5. In this work, response times were obtained from the records of the emergency response authorities.

\section{Experimental Stages}

The emergency responses recorded in each semester in the period between 2004 and 2015 were analyzed under three different prioritization conditions, which reflect the improvements introduced to the system during the analyzed time period. The first period in Table 5 presents data available from before the system's implementation. The first prioritization condition, introduced in January 2007, was the introduction of georeferenced maps. In January 2009, risk level according to the Municipality Risk Reduction Plan began to be considered in prioritizing responses. Finally, starting in January 2011, the surveyor's actual location was included as a prioritizing criterion. This system remains functional.

Thus, in the time period between 2004 and 2006, the digital response record included only the street address and postal code of the occurrence, without any cartographic check before the response.

Between 2007 and 2008, an area map as well as georeferencing data was offered to the surveyor. Thus, survey reports began to include not only street address and postal code, but also UTM coordinates. It is important to note that during this period, a simultaneous criterion was used to minimize the load for each surveyor.

Starting in 2009, areas classified as risk areas-and thus more vulnerable to disasters-started gaining higher priority in the response system. It was then possible to compile and interface, in the survey report map, geographic information with risk level, further prioritizing and supporting responses.

Since 2011, the assignment of the response team has included the geographical location of the survey team, preserving previously established prioritizing criteria based on risk areas and geographical location.

\section{Advantages and Difficulties Associated with the use of the System}

Some of the advantages observed during the system's trial in Juiz de Fora are that:

- The system provides managerial information with respect to the distribution of events in areas of geotechnical risk

- The system is a powerful basis for updating the geotechnical cartograms 
- The system makes it possible to detect and identify areas that were not previously considered risk areas but, due to continuous anthropic intervention as well as frequent emergency occurrence reports, points to a possible risk situation that requires more detailed geotechnical analysis

- The real-time input of emergency management authority reports allows the optimization of management response resources, avoiding response team overloads

- The system also uses real-time emergency management authority reports as an indication of collective emergency events and not as a set of isolated events

- The risk analysis module makes it possible for response teams to identify the relationship between reported events using their pertinence and/or proximity to risk areas, as well as to rescue instruments such as shelter locations, fire hydrants, community leaders and the authorities responsible for the care of minors in distress

- The system does not require knowledge or previous training in cartography or geoprocessing for its operation. All that is needed is the building's street address to coordinate all actions related to an occurrence

- As the access to databases and the system is open to various players in the emergency management community, they can all properly take part in timely and efficient decision-making

- Inter-departmental database integration solves the previous problem of non-communicating, decentralized and sometimes hard-to-access databases

- The system does not require specialist intervention and is self-sustaining from the continuous flux of emergency event reports

- It is natively supported by both Windows and Linux Systems

The main difficulties of using the system, observed during the case study application were:

- Very intense CPU usage

- The dependence of the system, as expected, on the accuracy and availability of reliable initial information

- The user can't create, edit and export data offline, disasters have often disrupted communications because of damages to internet communications

- No framework used, so the managed code can be slow

- All input data must have the same coordinate reference system and Datum

\section{Comparison and Discussion of Experimental Results}

Table 5 shows the total number of occurrences, the number of occurrences in risk areas and average response times, alongside the module improvements that include georeferencing of the surveyor location and the event, as well as the generation of occurrence maps.

It is evident from the data in Table 3 that response time has significantly decreased in association with the introduction of various aspects of the system. The progressive implementation of georeferencing and geoprocessing analysis in the response systems led to a response time reduction of up to $39 \%$, which results from optimizing the response team's route selection and the significant reduction in routing mistakes by the response team. Since the first semester of 2011, the system has been able to automatically send all new event data to the surveyor by email.

According to the system development priority help for maps, published at PJF - Prefeitura de Juiz de Fora. (2016).

In the above sites, Web-Based Emergency Management Preparedness Information System (WBEMIS), is referenced as "Sistema de Informações de Defesa Civil - SISDEC 3.0."

The system application for public policy promotion is available at: ACESSA.com - Juiz de Fora - Minas Gerais - Portal de Notícias (2006), PJF - Plano Municipal de Saneamento (2012), Universidade Federal de Santa Catarina - Centro Universitário de Estudos e Pesquisas sobre Desastres (2009).

\section{Conclusion}

The Web-Based Emergency Management Information System was shown to be an extremely important and useful tool to support evaluation information in the field, making it easier to make good decisions in regions classified as risk areas due to their geotechnical characteristics.

Perhaps more importantly than the local evaluation performed, the advance analysis of these risk areas can supply management information with the distribution of events in geotechnical risk areas. This, in turn, forms a basis for updating geotechnical cartograms, making it possible to detect areas that, although not previously included in the list of risk areas, may, due to continuous anthropic interventions and occurrence of emergency events, require their reclassification as risk areas requiring geotechnical evaluation.

In conditions where it is not common to have emergency management personnel with proper training and education in cartography and geoprocessing, this system has the great advantage of not requiring this knowledge for efficient operation: All that is needed is a 
building's street address in order to have all the information needed for a readily available response.

Lastly, the system makes it possible to prioritize responses, so that emergency response resources, normally scarce, can be directed to the most vulnerable areas, with a priority system based on objective risk criteria.

For the future scope, the system must incorporate an alert or alarm module, using neural network algorithm to warn the appropriate persons/authorities, in order to implement corrective measures, getting rain data in real time.

Developing hybrid mobile apps permitting synchronization with server and Real-time mapping module from multiple users, in this case, the facility management officials as well as the occupants in prevention activities.

\section{Acknowledgment}

The authors are grateful for supports from Civil Defense of the Municipality of Juiz de Fora for making the data available.

\section{Funding Information}

This research was developed by the School of Civil Engineering, UFF Federal Fluminense University.

\section{Author's Contributions}

Jordan H. Souza: Wrote the article as a leading author. Designed the research plan, participated in all programming and calculation, coordinated the data analysis and contributed to the writing of the paper.

Carlos A.P. Soares: Organized the study, participated in all experiments, programming and calculation and contributed to the writing of the paper.

Gislaine Santos: Participated in all experiments and in the data analysis also contributing to the writing of the paper and the data analysis.

Wainer S. Silva: Participated in all experiments and in the data analysis also contributing to the writing of the paper. Critically reviewed the manuscript.

\section{Ethics}

This article is original and contains unpublished material. The corresponding author confirms that the other author has read and approved the manuscript and no ethical issues involved.

\section{References}

ACESSA.com-Juiz de Fora-Minas Gerais-Portal de Notícias (2006) Web.
Alexander, D., L. Bramati and M. Simonetta, 2009. Emergency preparedness training and education in lombardy region, Italy: Survey of supply and demand. Nat. Hazards Rev., 10: 77-83. DOI: 10.1061/(ASCE)1527-6988(2009)10:3(77)

Assilzadeh, H., J.K. Levy and X. Wang, 2010. Landslide catastrophes and disaster risk reduction: A GIS framework for landslide prevention and management. Remote Sens., 2: 2259-2273. DOI: 10.3390/rs2092259

Avelar, A.S., A.L.C. Netto, W.A. Lacerda, L.B. Becker and M.B. Mendonça, 2013. Mechanisms of the recent catastrophic landslides in the mountainous range of Rio de Janeiro, Brazil. Landslide Sci. Pract., 4: 265 270. DOI 10.1007/978-3-642-31337-0_34

Carrara, A., F. Guzzetti, M. Cardinali and P. Reichenbach, 1999. Use of GIS technology in the prediction and monitoring of landslide hazard. Nat. Hazards, 20: 117-135. DOI: 10.1023/A:1008097111310

Carvalho, J.C., 2010. Gestão de riscos e encostas: implicações geotécnicas da ocupação e uso do solo e sua relação com a educação ambiental, com as limitações das normas técnicas e com a falta de efetividade das normas administrativas e jurídicas. Proceedings of the Congresso Brasileiro de Mecânica dos Solos Engenharia Geotécnica, (SEG' 10), XV COBRAMSEG ANAIS, Gramado, pp: 327-334.

Cascini, L., C. Bonnard, J. Corominas, R. Jibson and J. Montero-Olarte, 2005. Landslide Hazard and Risk Zoning for Urban Planning and Development. In: Landslide Risk Management, Hungr, O., R. Fell, R. Couture and E. Eberthardt (Eds.), Taylor and Francis, London, pp: 199-235.

CRED, 2015. Emergency events database EM-DAT. Centre for Research on the Epidemiology of Disasters. www.emdat.be/database

CPRM, 2011. Serviço geológico do Brasil. Seleção dos municípios críticos a deslizamentos. Nota explicativa. Companhia de Pesquisa de Recursos Minerais.

Cruden, D.M. and R. Fell, 1997. Landslide Risk Assessment. 1st Edn., Balkema, Rotterdam, ISBN10: 9054109149 , pp: 384.

Delmelle, E.M., H. Zhu, W. Tang and I. Casas, 2014. A web-based geospatial toolkit for the monitoring of dengue fever. Applied Geography, 52: 144-152. DOI: 10.1016/j.apgeog.2014.05.007

Dourado, F., A. Freitas and N. Fernandes, 2014. Radar Images Supporting Rescue and Recovery Actions for Landslide and Flood Disasters: A Rio de Janeiro State Case Study. In: Landslide Science for a Safer Geoenvironment, Sassa, K., P. Canuti and Y. Yin, (Eds.), Springer International Publishing, New York, pp: 551-555. 
Foster, C., C.V.L. Pennington, M.G. Culshaw and K. Lawrie, 2012. The national landslide database of Great Britain: Development, evolution and applications. Environ. Earth Sci., 66: 941-953. DOI: $10.1007 / \mathrm{s} 12665-011-1304-5$

Goldberg, D.W., J.P. Wilson and C.A. Knoblock, 2007. From text to Geographic Coordinates: The current state of geocoding. J. Urban Regional Inform. Syst. Assoc., 19: 33-46.

Karimi, H.A., M. Durcik and W. Rasdorf, 2004. Evaluation of uncertainties associated with geocoding techniques. Comput.-Aided Civil Infrastructure Eng., 19: 170-185. DOI: 10.1111/j.1467-8667.2004.00346.x

Kim, S., B. George and S. Shekhar, 2007. Evacuation route planning: Scalable heuristics. Proceedings of the 15th International Symposium on Advances in Geographic Information Systems, Nov. 07-09, ACM, New York, pp: 146-153. DOI: $10.1145 / 1341012.1341039$

Lan, H.X., C.H. Zhou, L.J. Wang, H.Y. Zhang and R.H. $\mathrm{Li}$, 2004. Landslide hazard spatial analysis and prediction using GIS in the Xiaojiang watershed, Yunnan, China. Eng. Geol., 76: 109-128. DOI: 10.1016/j.enggeo.2004.06.009

Lima, R.E., 2013. New Approach to Rapid Risk Evaluation in Disasters Related to LandslidesBrazil. In: Landslide Science and Practice, Margottini, C., P. Canuti and K. Sassa (Eds.), Springer Berlin Heidelberg, pp: 333-337.

Netto, A.L.C., A.M. Sato, A.S. Avelar, L.G.G. Vianna and I.S. Araújo et al., 2013. January 2011: The extreme landslide disaster in Brazil. In: Landslide Science and Practice, Margottini, C., P. Canuti and K. Sassa (Eds.), Springer Berlin Heidelberg, pp: 377-384.

Nichol, J.E. and M.S. Wong, 2005. Satellite remote sensing for detailed landslide inventories using change detection and image fusion. Remote Sens., 26: 1913-1926. DOI: $10.1080 / 01431160512331314047$

Odajima, T., S. Tsuchida, Y. Yamaguchi, T. Kamai and Y.O.P. Siagian, 1998. GIS and remote sensing based analysis of landslide hazards in Cianjur, West Java, Indonesia. Proceedings of the International Symposium on Application of Remote Sensing and Geographic Information System to Disaster Reduction, Mar. 3-4, Institute for Transfer of Industrial Technology, Japan, pp: 185-190.

PJF - Plano Municipal de Saneamento (2012) Web www.planodesaneamento.pjf.mg.gov.br/pdf/tomo_i _diagnostico_geral.pdf

PJF - Prefeitura de Juiz de Fora. (2016) Web www.pjf.mg.gov.br/noticias/imprimir_noticia.php?i dnoticia $=12081$
Rettig, A.J., S. Khanna and R.A. Beck, 2015. Open source REST services for environmental sensor networking. Applied Geography, 60: 294-300. DOI: $10.1016 /$ j.apgeog.2014.11.003

Sorensen, J.H., 2000. Hazard warning systems: Review of 20 years of progress. Nat. Hazards Rev., 1: 119-125. DOI: 10.1061/(ASCE)1527-6988(2000)1:2(119)

Tamima, U. and L. Chouinard, 2012. Framework for earthquake evacuation planning: Case study for montreal, Canada. Leadership Manage. Eng., 12: 222-230.

DOI: $10.1061 /($ asce $) \operatorname{lm} .1943-5630.0000198$

Tsou, M.H., 2004. Integrating web-based GIS and image processing tools for environmental monitoring and natural resource management. J. Geograph Syst., 6: 1-20. DOI: $10.1007 /$ s10109-004-0131-6

Universidade Federal de Santa Catarina - Centro Universitário de Estudos e Pesquisas sobre Desastres (2009). Web www.ceped.ufsc.br/wpcontent/uploads/2009/01/artigo-27.pdf

Van Westen, C.J., 2000. The modelling of landslide hazards using GIS. Surv. Geophys, 21: 241-255. DOI: 10.1023/A:1006794127521

Veyret, Y., 2007. Os Riscos. O Homem Como Agressor e Vítima do Meio Ambiente. 1st Edn., Contexto, São Paulo, pp: 319.

WB, 2012. Avaliação de perdas e danos. Inundações e deslizamentos na Região Serrana do Rio de Janeiro de 2011. World Bank.

Yin, R.K., 2009. Case study research: Design and methods. Beverly Hills.

Zandbergen, P.A., 2008. A comparison of address point, parcel and street geocoding techniques. Comput. Environ. Urban Syst., 32: 214-232.

DOI: 10.1016/j.compenvurbsys.2007.11.006 